\title{
The Effect of Transesophageal Echocardiography Probe Insertion in Endotracheal Tube Cuff Pressure in Adult Cardiac Surgical Patients.
}

\author{
Santosh Sharma Parajuli, Parbesh Kumar Gyawali, Suraj KC. \\ Department of Cardiac Anaesthesia, Shahid Gangalal National Heart Centre, Bansbari, Kathmandu, Nepal.
}

\author{
Corresponding Author: \\ Santosh Sharma Parajuli \\ Shahid Gangalal National Heart Centre, Bansbari, Kathmandu, Nepal. \\ E-mail: santoshparajuli77@hotmail.com
}

ORCID ID: https://orcid.org/0000-0001-7155-106X

Submitted date: $31^{\text {st January } 2021}$

Accepted date: $3^{\text {rd }}$ March 2021

Cite this article as: Parajuli S S, Gyawali P K, KC S et al. The Effect of Transesophageal Echocardiography Probe Insertion in Endotracheal Tube Cuff Pressure in Adult Cardiac Surgical Patients. Nepalese Heart Journal 2021; Vol 18 (1): 49-51.

\begin{abstract}
Background and Aims: Insertion of transesophageal echocardiography probe in cardiac surgical patient is a routine practice for surgical planning and decision making. However it may increase the endotracheal tube cuff pressure as it lies adjacent to the posterior wall of trachea. The aim of this study is to evaluate the changes in cuff pressure after insertion of the transesophageal echocardiography probe and after completion of initial manipulation of the transesophageal echocardiography probe during various examinations in adult cardiac surgical patients.

Methods: Thirty six patients undergoing elective cardiac surgery requiring Transesophageal Echocardiography (TEE) monitoring were enrolled in the study. After induction of general anesthesia and endotracheal intubation cuff pressure were measured at 3 points of time; just after intubation (T1), after transesophageal probe insertion (T2) and after initial completion of TEE study (T3). The mean increase in cuff pressure at various point of time were compared.

Results: The cuff pressure (mean $\pm \mathrm{SD}$ ) at T1, T2 and T3 were $24.61 \pm 2.72,30.22 \pm 5.61$ and $32.25 \pm 4.45 \mathrm{~cm}$ of $\mathrm{H}_{2} \mathrm{O}$ respectively. The cuff pressure increased significantly from T1 to T2 ( $<<0.001)$ and from T1 to T3 ( $<<0.001)$. The cuff pressure was $>30$ $\mathrm{cm}$ of $\mathrm{H}_{2} \mathrm{O}$ in $18(50 \%)$ of patients at $\mathrm{T} 3$ which was readjusted back to $25-30 \mathrm{~cm}$ of $\mathrm{H}_{2} \mathrm{O}$ by with drawing air from the cuff. Conclusion: Endotracheal tube cuff pressure should be routinely monitored either intermittently or continuously after transesophageal echocardiography probe insertion till it is in situ and pressure should be readjusted to avoid unwanted complications.
\end{abstract}

Keywords: Cuff Pressure; Endotracheal Tube; Transesophageal Echocardiography Probe.

DOI: https://orcid.org/10.3126/njh.v18i1.36785

\section{Background}

Cuffed endotracheal tube is routinely used to secure airway during general anesthesia in adult cardiac surgical patients. Mean capillary pressure in the tracheal wall is about $20 \mathrm{mmHg}\left(30 \mathrm{cmH}_{2} \mathrm{O}\right)$ and if the pressure exerted by an inflated tracheal tube cuff is above this value, it may result in reduced tracheal capillary blood flow. ${ }^{1,2}$ This excessive intracuff pressure may result in serious complications including airway problems such as post-operative sore throat, subglottic edema with stridor or tracheal stenosis., ${ }^{3,4}$

Transesophageal echocardiography (TEE) is routinely inserted after endotracheal intubation in cardiac surgical patients which helps in clinical decision making and other wide range of information during cardiac surgery. ${ }^{5}$ The posterior membranous wall of the trachea is in contact with the esophagus, ${ }^{6}$ so there might be the possibility of the TEE probe to compress the endotracheal tube cuff and increase the cuff pressure. ${ }^{7,8}$

(a) Nepalese Heart Journal. Nepalese Heart Journal retain copyright and works is simultaneously licensed under Creative Commons Attribution License CC - By 4.0 that allows others to share the work with an acknowledge of the work's authorship and initial publication in this journal 
The aim of this study is to evaluate the changes in cuff pressure after insertion of the TEE probe and after completion of initial manipulation of the TEE probe during various examinations in adult cardiac surgical patients. The outcome of this study can be useful to optimize the cuff pressure value after TEE probe insertion in order to avoid the unwanted adverse effects in our setup in future.

\section{Methods}

After obtaining institutional review board approval and written informed consent of patient, all the adult patients requiring cardiac surgery who underwent intraoperative trans-esophageal echocardiographic evaluation were selected for this study.

This was the prospective observational study performed at Shahid Gangalal National Heart Center of Nepal. All adult cardiac surgical patients more than 18 years of age who were scheduled for elective cardiac surgery requiring intraoperative TEE monitoring were included in the study. However patients' refusal, patient requiring emergency surgery, patients with tracheal stenosis, patients with tracheoesophageal fistula, patients with previous esophageal surgery, patients with esophageal varices, patients with Barrett esophagus, patients with esophageal hernia, patients with descending thoracic aorta aneurysm, patients with dysphagia and patients with vocal fold palsy were excluded from the study.

Total 36 patients were taken as our sample size for the study to have $95 \%$ confidence interval and power of $90 \%$ from previous study done by Borde DP et al. ${ }^{9}$

After the patient was brought to the operation theatre, standard monitoring such as electrocardiography and pulse oximetry were applied. Invasive blood pressure monitoring line and central venous catheter through right internal jugular vein were inserted under standard aseptic precautions. Induction of anesthesia was done with midazolam, fentanyl, and propofol. In all cases vecuronium was used as muscle relaxant. After induction of anesthesia, appropriate sized ( 7 for female and 7.5 for male) cuffed high volume low pressure endotracheal tube (ETT-portex, Smiths Medical ASD, INC, USA) was used to secure the airway. The proper placement of the ETT was confirmed with appeareance of end tidal carbondioxide $\left(\mathrm{EtCO}_{2}\right)$ tracing and auscultation over chest for bilateral air entry. The cuff of the ETT was slowly inflated using the air leak technique by putting the stethoscope on the suprasternal notch with slow inflation of the cuff until there will be no audible air leak while holding continuous positive airway pressure (CPAP) of $20 \mathrm{cmH}_{2} \mathrm{O}$ with the head and neck in the neutral position to seal the airway. Mechanical ventilation was started with volume-controlled mode with the tidal volume of $8 \mathrm{ml} / \mathrm{kg}$, respiratory rate of 12 per minute, inspiratory/expiratory ratio of $1: 2$ and fraction of inspired oxygen $\left(\mathrm{FiO}_{2}\right) 0.6$ with an air-oxygen mixture with isoflurane. Positive end-expiratory pressure was not applied. After the ETT cuff was inflated, the baseline cuff pressure was measured using a manometer and was recorded. After that, TEE probe (Philips EpiQ7, USA) was inserted after adequate lubrication and a brief jaw thrust maneuver. Experienced cardiac anesthesiologist inserted the probe and manage all cases. Bite guard was applied after TEE probe placement. If there was failure in blind insertion of TEE probe after two attempts, the probe was using direct laryngoscopy, or the procedure was abandoned if significant resistance was encountered. These patients were excluded from the study. Any TEE associated complications (e.g., dental injury, upper gastrointestinal bleeding, and esophageal/gastric injury) were noted. The cuff pressure were recorded at three points of time; before the insertion of the TEE as a baseline (T1); immediately after TEE probe insertion (T2) and immediately after completion of initial TEE examination (T3). If the pressure was found to be persistently $>30 \mathrm{~cm}$ of $\mathrm{H}_{2} \mathrm{O}$ at T3, this was adjusted back to $25-30 \mathrm{~cm}$ of $\mathrm{H}_{2} \mathrm{O}$. Alternatively, air was added to the cuff, if there was an audible air leak or if there was inadequate ventilation because of loss of tracheal seal.

Mean cuff pressure was compared between pairs of time points (T1 vs. T2 and T1 vs. T3) using student T-test. A P value $<0.05$ was considered as significant. The Statistical Package for the Social Sciences (SPSS) version 22.0 was used to perform data analysis.

\section{Results}

Thirty six patients were enrolled in the study out of which 22 $(61.1 \%)$ were male and $14(38.9 \%)$ were female. In all cases TEE was inserted in first attempt without any complications. There was no any audible air leak noticed from the endotracheal tube cuff during the study. The demographic data of patients studied is shown in Table 1. The cuff pressure $(m e a n \pm \mathrm{SD})$ at $\mathrm{T} 1, \mathrm{~T} 2$ and $\mathrm{T} 3$ were $24.61 \pm 2.72,30.22 \pm 5.61$ and $32.25 \pm 4.45 \mathrm{~cm}$ of $\mathrm{H}_{2} \mathrm{O}$ respectively (figure 1). The cuff pressure increased significantly from $\mathrm{T} 1$ to $\mathrm{T} 2$ $(p<0.001)$ and from T1 to T3 $(p<0.001)$. The cuff pressure was $>30$ $\mathrm{cm}$ of $\mathrm{H}_{2} \mathrm{O}$ in $18(50 \%)$ of patients at $\mathrm{T} 3$ which was readjusted back to $25-30 \mathrm{~cm}$ of $\mathrm{H}_{2} \mathrm{O}$ by with drawing air from the cuff.

Table 1: Demographic variables.

\begin{tabular}{ll}
\hline Variables & \\
\hline Gender Male:Female & $22: 14$ \\
\hline Age in years Median (Range) & $40.5(18-74)$ \\
\hline Weight in kg Median (Range) & $60.50(40-85)$ \\
\hline Height in cm Median (Range) & $160.00(140-185)$ \\
\hline BMI in $\mathrm{kg} / \mathrm{m}^{2}$ Median (Range) & $23.59(16.76-33.16)$ \\
\hline
\end{tabular}

Figure 1: Change in cuff pressure at 3 points of measurement.

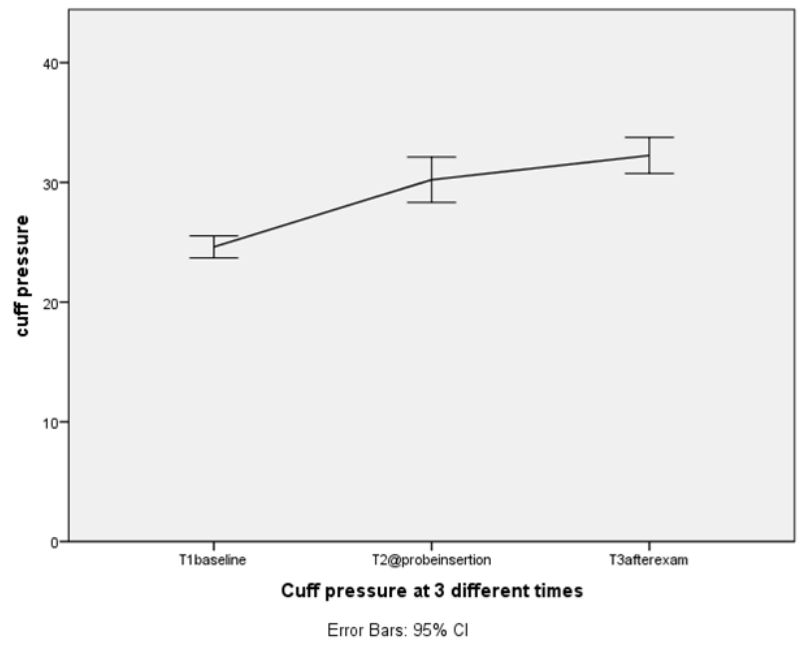

\section{Discussion}

Our study has shown that the use of TEE will increase the cuff pressure and in $50 \%$ of the cases the pressure has gone above $30 \mathrm{~cm}$ of $\mathrm{H}_{2} \mathrm{O}$ which might lead to decrease in tracheal mucosal blood flow. As trachea is composed of 16-22 C-shaped cartilages with incomplete ring at its posterior surface which is in contact with the esophagus, ${ }^{6}$ 
inserting TEE probe in the esophagus exerts pressure in this posterior part of trachea leading to unpredictable increase in ET-tube cuff pressure. One animal model study has shown that sustained increase of tracheal mucosal pressure of more than $30 \mathrm{~cm}$ of $\mathrm{H}_{2} \mathrm{O}$ for more than 15 minutes leads to histological tracheal mucosal lesion. ${ }^{10}$

TEE has been widely used as a monitoring tool for decision making and surgical planning in cardiac surgery. ${ }^{11}$ Though considered to be relatively safe, there is an incidence of $1.4 \%$ complication related to TEE including dysphagia, vocal cord and laryngeal injury and esophageal perforation. ${ }^{12}$ Besides this as TEE probe is just adjacent to trachea, the increase in cuff pressure can lead to post-operative sore throat, subglottic edema with stridor or tracheal stenosis in cardiac surgical cases where TEE probe stays in situ for prolong period and there is also periods of decreased perfusion pressure in hypotensive phages. ${ }^{3,4}$

Various studies has shown that in different periods of TEE insertion and examination, the cuff pressure has increased. In a study done by Borde DP et al. ${ }^{9}$ The mean cuff pressure increased form baseline $22 \pm 3$ to $38 \pm 10 \mathrm{~cm}$ of $\mathrm{H}_{2} \mathrm{O}$ after insertion of probe and to $30 \pm 6 \mathrm{~cm}$ of $\mathrm{H}_{2} \mathrm{O}$ after TEE examination which were statistically significant. Similar study done by Tan $\mathrm{PH}$ et al. ${ }^{7}$ also found similar results in consistent to our study where mean cuff pressure increased from $27.7 \pm 1.5$ to $36.2 \pm 6.4 \mathrm{~cm}$ of $\mathrm{H}_{2} \mathrm{O}$ after TEE probe insertion and $45 \%(17 / 38)$ of patients had a cuff pressure of more than $35 \mathrm{~cm}$ of $\mathrm{H}_{2} \mathrm{O}$.

Kim TK et $\mathrm{al}^{8}$. compared the effect of TEE probe insertion in single and double lumen ET-tube and found that cuff pressure increased in both cases after TEE insertion but was more profound in double lumen group.

On the basis of all these findings and our study, we recommended to measure the cuff pressure timely and reduce it to the safety limit to avoid the unwanted adverse effects. The main limitation of our study was that we recorded the cuff pressure intermittently, however as TEE probe remains in situ till the end of surgery we also recommend to do continuous cuff pressure measurement and adjustment accordingly till the TEE probe is in situ.

\section{Conclusion}

The endotracheal tube cuff pressure significantly increases after TEE probe insertion and its manipulation even above the safety limit of $30 \mathrm{~cm}$ of $\mathrm{H}_{2} \mathrm{O}$. So, cuff pressure should be routinely monitored either intermittently or continuously after TEE probe insertion till it is in situ and pressure should be readjusted to avoid unwanted complications.

Conflict of Interest: We declare no perceived or potential conflicts of interest within past 36 months related to this study.

\section{Acknowledgement: None}

Sources of Support and Funding: Department of Cardiac Anesthesia, Shahid Gangalal National Heart Centre, Bansbari, Kathmandu, Nepal.

\section{References}

1. Leigh JM, Maynard JP. Pressure on the tracheal mucosa from cuffed tubes. British Medical Journal 1979; 1:1173-4. https://doi.org/10.1136/bmj.1.6172.1173
2. Seegobin RD, van Hasselt GL. Endotracheal cuff pressure and tracheal mucosal blood flow: endoscopic study of effects of four large volume cuffs. British Medical Journal 1984; 288: 965-8. https://doi.org/10.1136/bmj.288.6422.965

3. Suzuki N, Kooguchi K, Mizobe T, et al. Postoperative hoarseness and sore throat after tracheal intubation: effect of a low intracuff pressure of endotracheal tube and the usefulness of cuff pressure indicator. Masui 1999; 48: 1091-5. PMID: 10554500 .

4. Desle'e G, Brichet A, Lebuffe G, et al. Obstructive fibrinous tracheal pseudomembrane. A potentially fatal complication of tracheal intubation. American Journal of Respiratory Critical Care Medicine 2000; 162: 1169-71. https://doi.org/10.1164/ ajrccm.162.3.9910047

5. Kolev N, Brase R, Swanevelder J, et al. The influence of transoesophageal echocardiography on intra-operative decision making. A European multicentre study. Anaesthesia 1998; 53: 767-73.

https://doi.org/10.1046/j.1365-2044.1998.00341.x

6. Campos JH. Update on tracheobronchial anatomy and flexible fiberoptic bronchoscopy in thoracic anesthesia. CurrOpinAnaesthesiol 2009;22:4-10.

https://doi.org/10.1097/ACO.0b013e32831a43ab

7. Tan PH, Lin VC, Chen HS, et al. The effect of transesophageal echocardiography probe insertion on tracheal cuff pressure. Anaesthesia 2011;66:791-5. https://doi.org/10.1111/j.1365-2044.2011.06789.x

8. Kim TK, Min JJ, Seo JH, et al. Increased tracheal cuff pressure during insertion of a transoesophagealechocardiography probe: A prospective, observational study. Eur J Anaesthesiol 2015;32:549-54. https://doi.org/10.1097/EJA.0000000000000204

9. Borde DP, Pande S, Asegaonkar B, Khade S, George A, Joshi S. Does the endotracheal tube cuff pressure increases with transesophageal probe insertion?. Annals of Cardiac Anaesthesia. 2020 Oct 1;23(4):460. https://doi.org/10.4103/aca.ACA_52_19

10. Nordin U. The trachea and cuff-induced tracheal injury. An experimental study on causative factors and prevention. Acta oto-laryngologica. Supplementum.1977 Jan 1;345:1-71. PMID: 335778

11. Borde DP, George A, Joshi S, et al. Variations of transesophageal echocardiography practices in India: A survey by Indian College of Cardiac Anaesthesia. Annals of cardiac anaesthesia. 2016 Oct;19(4):646. https://doi.org/10.4103/0971-9784.191580

12. Purza R, Ghosh S, Walker C, et al. Transesophageal echocardiography complications in adult cardiac surgery: a retrospective cohort study. The Annals of thoracic surgery. 2017 Mar 1;103(3):795-802. https://doi.org/10.1016/j.athoracsur.2016.06.073 